\title{
UV curable hard coatings on plastics
}

\author{
S. Sepeur*, N. Kunze, B. Werner, H. Schmidt \\ Institut für Neue Materialien gem. GmbH, Saarbrïcken, Germany
}

\begin{abstract}
A photochemically curable transparent hard coating material has been developed to improve the wear resistance of organic polymers. Methacrylate functionalized silanes and nanoscaled boehmite particles were used for the preparation of the UV curable hard coatings by the sol-gel technique. The inorganic network is formed as a result of the controlled hydrolysis and condensation of the methacryloxysilanes in the presence of nanoparticles (particle size: $15 \mathrm{~nm}$ ). The hydrolysis and condensation of the methacryloxy silane, for two hours in presence of boehmite nanoparticles ( $43 \mathrm{wt} . \%$ ), at $100^{\circ} \mathrm{C}$ leads to a degree of condensation of $80 \%$ of the inorganic network, as determined by ${ }^{21} \mathrm{Si}-\mathrm{NMR}$ spectroseopy. The organic network is formed by photoinitiated polymerisation of the methacrylic-functions in only a few minutes, using UV light from a $\mathrm{Hg}$ high pressure lamp. Transparent coatings on plastic substrates (PC, PMMA) were produced by spray coating with good uptical quality and thicknesses of several micrometers. The transparent coatings show excellent adhesion on PMMA and PC (GT/TT $=0 / 0$, DIN 53151), even without using primers, and also good abrasion resistance after the Taber abraser test with haze values of $10 \%$ after $10(0)$ cycles (CS $10 \mathrm{~F}$ rolls, $5,4 \mathrm{~N}$, DIN 52347). The water exposition test $\left(65^{\circ} \mathrm{C}\right.$, deionized water) and the Suntest, without using filters, did not result in any crack formation, loss of adhesion or yellowing within the test period of two weeks.
\end{abstract}

Keywords: UV curable; Hard coating; Sol-gel; Silane; Nanoparticles; Abrasion resistance; Condensation; Polymerisation

\section{Introduction and state of the art}

Mechanical impacts on polymers lead to a loss in transparency and therefore to a reduction in the performance of the material. To avoid this effect, coatings have been developed to protect the plastic surfaces.

Inorganic coatings produced by gas phase or vacuum deposition (CVD, PVD), show a good abrasion resistance in general, but in addition to high costs, there is often the problem of poor adhesion because of the different thermal expansion coefficients of the substrate and the coating, especially when thick layers with sufficient mechanical impact resistance have to be used. The use of this technique is also limited by crack formation through indentation impact, as a consequence of very different moduli of elasticity in the case of inorganic coating materials on plastics [1,2].

The coating of polymer surfaces by wet chemical processes (e.g. sol-gel) is in most cases an interesting alternative compared to gas phase or vacuum techniques $[3,4]$.Thermally hardened sol-gel systems improve the abrasion resistance of uncoated polymers after the Taber abraser

" Corresponding author. Tel.: +49-681-9300-333; fax: +49-681-9300242.

E-mail address: sepeur@inm-gmbh.de (S. Sepeur) test from haze values about $50 \%$ up to $15 \%$ [5]. An improvement in abrasion resistance to give a value comparable to that of glass (haze value: $2 \%$ ) can be achieved by nanotechnologies via incorporation of nanoscaled $\mathrm{AlOOH}$ particles in sol-gel systems [6,7]. These systems, hardened at temperatures between $100-150^{\circ} \mathrm{C}$, are suitable for polymers with sufficient temperature stability.

Plastics sensitive to high temperatures (e.g. PMMA, PET) have to be coated by UV-curing systems since the thermally cured systems described show only poor results when cured below $100^{\circ} \mathrm{C}$. Such coating materials also possess other advantages such as shorter curing times and good adhesion without pretreatment. Commercially available UV-polymerizable hard coating systems are distributed by SDC Coatings Inc. [8]. They show good adhesion onto PMMA and PC and moderate abrasion resistance after the Taber Abraser test with haze values of $8-12 \%$ after 500 cycles.

The aim of this work was the development of a fast UV curing hard coating material for surface protection of PC and PMMA. Further characteristics of the coating material should be ease of application via wet chemically methods and an essential improvement of the abrasion resistance. In this article, the mechanisms of sol synthesis will be described and the results of the fundamental structure $\left({ }^{29} \mathrm{Si}-\mathrm{NMR}, \mathrm{UV} / \mathrm{VIS}, \mathrm{SEM}\right)$ are presented. The mechanical properties were examined by different test methods to obtain 
results pertaining to scratch resistance, adhesion, abrasion resistance, UV- and water stability.

\section{Experimental}

\subsection{Synthesis of the coating materials}

$136.84 \mathrm{~g}$ of nanoscaled AlOOH particles (Sol P3, particle size $15 \mathrm{~nm}$, Degussa) were added to $248.8 \mathrm{~g}$ (1 mol) of methacryloxypropyltrimethoxysilane (MPTS, Hüls) and stirred while heating up to $100^{\circ} \mathrm{C}$. After rapid addition of $36.0 \mathrm{~g} \mathrm{(} 2 \mathrm{~mol})$ deionized water the mixture is stirred for 2.5 $\mathrm{h}$ at $100^{\circ} \mathrm{C}$. The final mixture contained $43.2 \%$ by weight $\mathrm{AlOOH}$

\subsection{Preparation of the coatings}

To obtain a processable coating system the above described material is diluted to a solid content of $45 \%$ with 1-butanol. $3 \mathrm{~mol} \%$ /MPTS benzophenone (Fluka) as UV initiator and 0.5 wt.\% BYK 306 (Byk) as additive are added. The coating system is applicated by spin coating $(1500 \mathrm{rpm})$ on $100 \times 100 \mathrm{~mm}$ PC-plates (MAKROLON 3103, Bayer). The system is cured by $\mathrm{Hg}$ high pressure lamps with a power of $55 \mathrm{~mW} / \mathrm{cm}^{2}$ and a running belt velocity of $0.8 \mathrm{~m} / \mathrm{min}$ (Beltron).

\subsection{Characterization}

To determine the inorganic cross linking grade of the coating material, ${ }^{29} \mathrm{Si}$-NMR spectra were recorded (Bruker). The quantitative interpretations of the spectra were carried out with the INVGATE measurement software to suppress the Kern-Overhauser-effect. According to the different chemical shifts of the hydrolysis and condensation species of the silane components, the inorganic condensation grade was calculated by integration of the individual signals (Eq. (1)).

$K(\%)=\frac{T^{1}+2 T^{2}+3 T^{3}}{3\left(T^{0}+T^{1}+T^{2}+T^{3}\right)}$

(1)where $T$ is the Si-species with three hydrolysable silanecompounds, $x$ in $T^{x}$ is the number of siloxane bounds on the Si-atom, $K$ is the condensation grade.

The micro structure analysis of the hard coatings was conducted with a high resolution scanning electron microscope (FEG, type 6400F, JOEL). To reduce the build up of electrostatic charges, a $2 \mathrm{~nm}$ thick Au-layer was sputtered on the coating. The abrasion resistance was measured with the Haze Gard plus (Byk Gardner) after 1000 cycles Taber Abraser (Fa. Erichsen, CS 10F rolls, 5.4 N). Haze is given in percentage $(\%)$. The scratch resistance was determined by a Vickers diamond (Leitz), which was pulled over the coating with different weights. The value of scratch resistance is given by the lowest weight, which causes a scratch mark in the coating, as visible under a microscope. The adhesion of the coating was determined by lattice cut/tape test (Erichsen, ASTM D 3359, DIN 53151). The graduation ranges from GT/TT $=0$ (excellent adhesion) to $\mathrm{GT} / \mathrm{TT}=$ 5 (no adhesion). The UV stability of coated PC-plates was tested in a Suntest CPS (Heraeus), without filters, and a sunlamp treatment of $765 \mathrm{~W} / \mathrm{cm}^{2}$. After 14 days, the plates were visually inspected for cracks and yellowing. The water stability was tested in deionized water at $65^{\circ} \mathrm{C}$. After 14 days of exposure the coatings were visually inspected for cracks and removals and adhesion was remeasured.

\section{Results}

To quantify the degree of the inorganic network cross linking of the methacryloxypropyl-trimethoxysilane in the sol-gel process, the condensation grade was determined with ${ }^{29} \mathrm{Si}-\mathrm{NMR}$. In addition, the influence of $\mathrm{AlOOH}$ particles on hydrolysis and condensation of the silane component were investigated. The NMR spectra of the silane component in presence of $\mathrm{AlOOH}$ particles and of the pure silane component under the same conditions are shown in Fig. 1.

Spectrum in Fig. Ib shows two fold linked (55\%) and three fold linked (37.5\%) silanes. The proportion of one fold linked silanes is only $5.5 \%$. The condensation grade of the hydrolysate is calculated to be $80-85 \%$ (Eq. (1)). The condensation grade of the hydrolysis and condensation of silanes without the $\mathrm{AlOOH}$ particles (spectrum Fig. 1a) is calculated to be only $70 \%$. The different condensation grades with/without $\mathrm{AlOOH}$ particles can be explained by the Lewis acid activity of the $\mathrm{Al}-\mathrm{OH}$ group on the hydrolysis and condensation reaction of the silanes compounds. This effect was already observed for the hydrolysis of 3glycidyloxypropyltrimethoxysilanes in the presence of AlOOH particles [6]. To get accurate information about the coating's microstructure, the samples were examined in the scanning electron microscope (Fig. 2).

The incorporation of $10-15 \mathrm{~nm}$ plate-like $\mathrm{AlOOH}$ particles in the siloxane matrix leads to homogeneous, density packed networks, containing no pores. The influence of the nanoscaled particles on the mechanical properties of the coating was determined by measuring the haze-values of coatings with different $\mathrm{AlOOH}$ contents (Fig. 3).

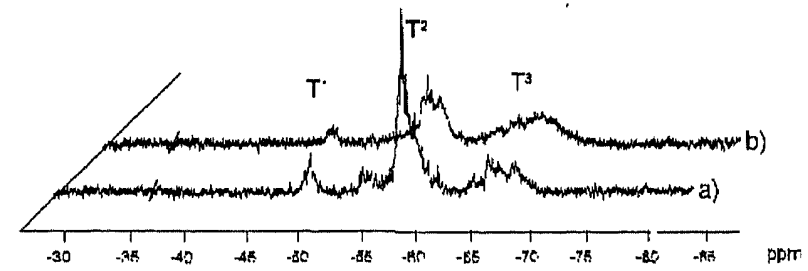

Fig. 1. $200 \mathrm{MHz}{ }^{29} \mathrm{Si}-\mathrm{NMR}$ spectra of methacrylic functionalized silanes (MPTS) after $1 \mathrm{~h}$, hydrolysis with water (a) without nano scaled $\mathrm{AlOOH}$ and (b) in the presence of $43.2 \mathrm{wt} . \% \mathrm{AlOOH}$. 


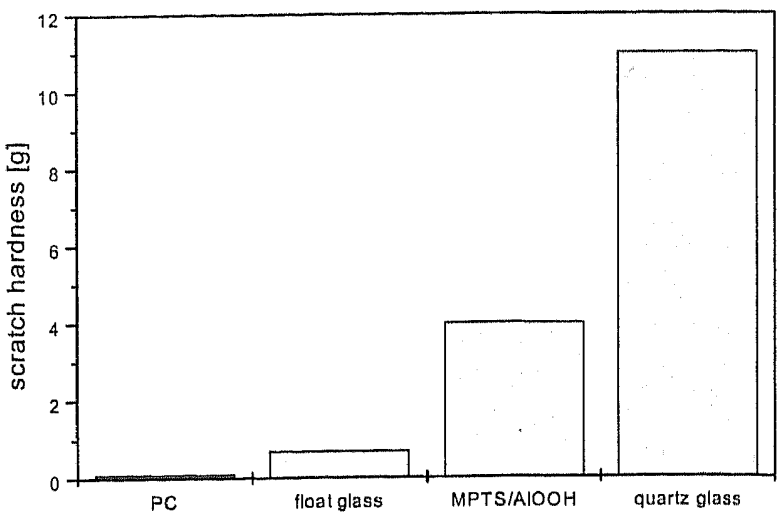

Fig. 4. Scratch hardness of different substrate materials (PC, float glass, quartz glass) compared with the matrix system of 43.2 wt. \% AlOOH on PC. coating thickness: $5 \mu \mathrm{m}$.

Fig. 2. REM picture of a UV-hardened methacrylic functionalized silane coating with 43.2 wt.\% AlOOH on PC.

As shown in Fig. 3 the abrasive resistance is a function of the AlOOH concentration in the coatings. The haze values decrease with rising filler content from $42 \%$ (without $\mathrm{AlOOH}$ particles) to $9-10 \%$ (with $43.2 \mathrm{wt} \% \mathrm{AlOOH}$ ). The uncoated polymer shows haze values of about 45$50 \%$. This is a distinct improvement on the mechanical properties of the coating. At higher filler contents $>45$ wt. \% AlOOH) agglomeration and sedimentation of the particles can be observed as well as an increase in the viscosity of the sols (pasty or solid) leading to unprocessable coating systems. To sum it up it can be said that the haze value is still away from float glass but it is at a very interesting level compared to existing UV curable hard coatings.

To complete the characterisation, scratch tests were performed using a Vickers diamond as described in the experimental part. Coatings with a filler content of 43.2

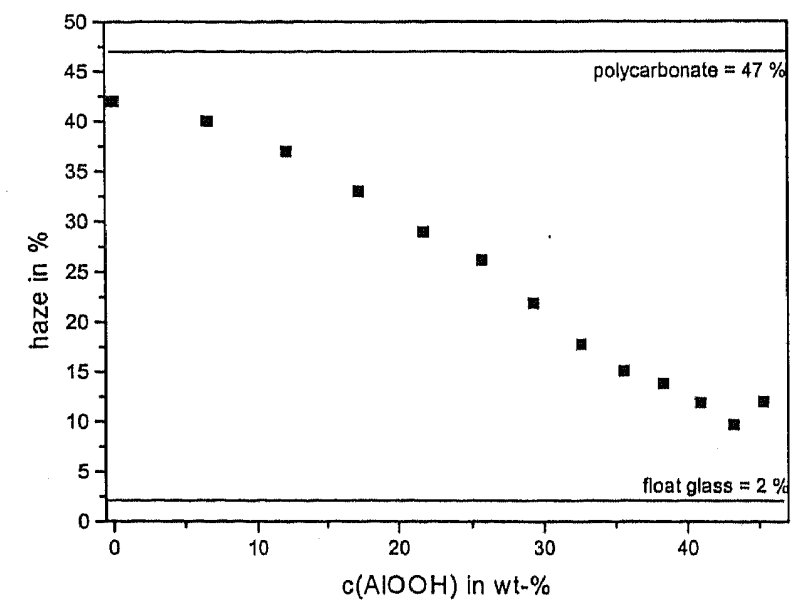

Fig. 3. Abrasive resistance (\% haze) [5] in dependence on AlOOH concentration compared to floatglass (haze $=2 \%$ ) and polycarbonate (haze $=47 \%$ ). Coated substrate: PC, UV-hardened, coating thickness: 5 $\mu \mathrm{m}$.

wt.\% AlOOH were produced, applied to PC and hardened with UV light. The scratch hardness was compared with uncoated PC, float glass and quartz glass (Fig. 4).

It is shown in Fig. 4, that the scratch hardness of uncoated PC has a value of $0.5 \mathrm{~g}$, the value of uncoated float glass is 1 $\mathrm{g}$ and that of quartz glass $11 \mathrm{~g}$. The coated PC exhibits a value of about $4 \mathrm{~g}$. This is due to the 'hard-elastic' behaviour of the coating, a property which float glass surfaces to not exhibit in the same way.

Investigations of the adhesion of AlOOH filled, UV cured, coating systems showed, that without pretreatment of the surface excellent adhesion is given $(\mathrm{GT} / \mathrm{TT}=(0 /())$. The weathering exposure stability was tested on the waterand UV stability of the coated substrates. The water exposure test in deionized water at $65^{\circ} \mathrm{C}$ for 14 days did not lead to any changes in optical or adhesive properties. The stability against UV light was proved in the Suntest without filter. After 21 days of irradiation no optical deterioration in the coating was detected.

\section{Conclusion and outlook}

The sol-gel synthesis of a highly filled nanocomposite material with surface modified nano- particles based on AlOOH and MPTS, results in a radical polymerizable agglomeration free coating material. It is possible to produce processable, and after application, rapid UVcurable $(2-3 \mathrm{~min})$ coating systems. The abrasive and scratch resistance of these coatings is substantially improved and the adhesion to $\mathrm{PC}$ is attained without pretreatment. The coating material can be adjusted to different coating techniques by variation of the solid content (viscosity).

With this UV curable base system numerous application fields are opened up, e.g. the refinement of polymer parts in automotive industry, household or ophthalmics. With the incorporation of additional functionalities, such as UV protection, hydrophilic or hydrophobic surfaces, antireflec- 
tion and antistatic properties along with the good mechanical properties, a huge application field is possible.

\section{References}

[1] H.K. Pulker, SPIE, 1275 (1990) 80.

[2] J.D. Basil, C.-C, Lin, R.M. Hunia, Offenlegungsschrift US 5385964 (1995) (3101.

[3] H. Schmidt, J. Sol-Gel Sci. Technol. 1 (1994) 217.

[4] H. Schmidt, Potential und Anwendungsmöglichkeiten von ORMOCE-
Ren, in: D. Lillack, B. Vierkorn-Rodolph (Eds.), Proc. Symp. Materialforschung, Band 1, Grundlagen, Poster und Vorträge, PLR/KF, Jülich, 1988, pp. 722-745.

[5] K.H. Haas, S. Amberg-Schwab, K. Rose, G. Schottner, GAK 2 (1997) $102-110$.

[6] E. Geiter, Dissertation, Universität Saarbrücken, 1997.

[7] R. Kasemann, H. Schmidt, E. Arpac, V. Gerhard, Offenlegungsschrift DE 4338361 (11.05.95).

[8] A. Guest, M. Misra, M. Tilley, SiF News, Issue no. 8, April 1997, pp. 20-23. 